\title{
The Universality and Cultural Specificity of Emotions through a Comparative Semantic Analysis of Emotion Terms in English and MA
}

\author{
Khalid Elasri \& Abdelhakim Boubekri
}

Mohammed V University, Morocco

\begin{abstract}
Johnson-Laird \& Oatley's analysis of emotion terms in English reveals that these terms are organised in a semantic field encompassing categories that denote generic emotions, basic
\end{abstract}

Khalid Elasri (First author)

Assitant Professor, Department of Languages, Mohammed V University, Morocco

Email: elasrik@gmail.com

Abdelhakim Boubekri (Corresponding author)

Researcher, Department of Languages, Mohammed V University, Morocco

Email: boubekri755@gmail.com

Received 28, February, 2020; Revised 16, April, 2020; Accepted 18, June, 2020

Copyright $\odot 2020$ Language Research Institute, Sejong University

Journal of Universal Language is an Open Access Journal. All articles are distributed online under the terms of the Creative Commons Attribution Non-Commercial License

(http://creativecommons.org/licenses/by-nc/3.0) which permits unrestricted non-commercial use, distribution, and reproduction in any medium, provided the original work is properly cited. 
emotions, emotional relations, caused emotions, causatives, emotional goals, and complex emotions. All the emotions are based on five modes: happiness, sadness, anger, fear, and disgust. This approach, termed 'a theory of communication', served a communicative function both within the brain and within social groups. However, whether this theory is applicable to all languages remains unspecified, that is, whether emotions of all languages are organized across these five modes, thereby rendering these modes universal, is not yet clear. Therefore, the present study attempts to assess the universality of this theory by investigating the emotion lexicon of Moroccan Arabic (MA) through a corpus including examples given by 29 native speakers of this language. A semantic analysis of the emotion terms shows that they are organized in the same categories found in the English language. Nevertheless, the highest category in MA consists of causative emotions, indicating that, unlike English, emotions in MA arise as relational phenomena, embedded in social situations.

Keywords: emotion, semantic analysis, emotion category, semantic field

\section{Introduction}

Emotions have been the focus of attention of researchers in many disciplines, including linguistics, psychology, philosophy, biology, and anthropology. Darwin (1872/1998) is considered to be the first major synthesizer of ideas about the nature of emotions. According to him, the concept of evolution does not only apply to the evolution of physical structures, such as skeletons and sensory receptors, but also to the behaviour and the emotions expressed by humans and lower animals. Darwin provided descriptions of facial expressions, and he argued for the universality of these expressions. Among the evidence that he suggested for his theory of evolution was the similarity of human emotions to those of animals which express 
them as reactions to basic problems of life. He wrote: "With mankind some expressions, such as the bristling of hair under extreme terror, or the uncovering of the teeth under that of furious rage, can hardly be understood, except on the belief that man once existed in a much lower and animal-like condition. The commonality of certain expressions in distinct though allied species, as in the movement of the same facial muscles during laughter by men and by various monkeys, is rendered somewhat more intelligible, if we believe they're descended from a common progenitor." (Darwin 1872/1998: 12).

The central organizing idea of Darwin is that emotions are evolved phenomena with important survival functions as they have solved certain problems in past species. Accordingly, the same emotions should be observed in all humans; And they should also be expressed in distinct cultures. These two hypotheses are investigated by Ekman et al. (1969). They took over 3,000 photos of different people asked to express six emotions - anger, disgust, fear, happiness, sadness, and surprise - according to Darwin's descriptions of the muscle configurations. These photos were shown to participants in Japan, Brazil, Argentina, Chile, and the United States. The participants were given a list of emotion words (translated into the relevant languages) and asked them to match the emotional facial expressions in the photos with one of the emotion words on the list. Across the five cultures, participants recognized the emotional facial expressions by matching them with the correct emotion words at levels greater than chance. This led Ekman and his colleagues to acknowledge the universality of emotional facial expressions.

Although adopting a completely different methodology, JohnsonLaird \& Oatley (1989)'s study shows that emotion terms in English are organised in a semantic field encompassing emotion categories that 
88 The Universality and Cultural Specificity of Emotions through

denote generic emotions, basic emotions, emotional relations, caused emotions, causatives, emotional goals, and complex emotions. All the emotions are based on five emotional modes, namely happiness, sadness, anger, fear, and disgust. Hence, their linguistic analysis of emotions confirms Ekman and his colleagues' hypothesis of the universality of the basic emotions.

\subsection{The Aim of the Paper}

The aim of this paper is to explore the semantic field of emotions in Moroccan Arabic (MA), a variety of Standard Arabic (SA) that is hardly researched as far as this area of research (emotions and language) is concerned. The paper categorises and identifies the terms of these emotions and their semantic organisation in this variety. It further discusses the universality and cultural specificity of emotions through a comparative semantic analysis of emotion terms in English and MA.

\subsection{Research Questions}

1. Which mental states in MA are considered by native speakers to describe emotions?

2. How are emotions organised semantically in MA?

3. Are MA emotion terms organised semantically in ways similar to English?

4. What does the semantic analysis of emotions in MA reveal about universality/cultural specificity of emotions? 


\subsection{Significance of the Study}

The findings of the study will add to the relatively limited literature on emotions in MA and also serve as a basis for further research into other areas including the language of emotions, and emotions and culture. It is also hoped that the findings of this study will add to the literature on universality/cultural specificity of emotions.

\subsection{Organization of the Paper}

Beyond the introduction, the paper is organized into four sections. The second section discusses the Johnson-Laird \& Oately's theory of emotions and its application to English language. It further discusses the status of MA. The third section explains the methodology followed in this study through explaining the participants' background, data collection procedure, and data analysis procedure. The results of the findings are presented in the fourth section. The last section discusses and recapitulates the findings of the study.

\section{Review of the Literature}

\subsection{Semantic Organization of Emotions in English}

Johnson-Laird \& Oatley (1989)'s semantic analysis of English emotion terms distinguishes seven main types of emotion words which denote: generic emotions, basic emotions, emotional relations, caused emotions, causatives, emotional goals, and complex emotions. The analysis of these emotion words reveals that there are 109 emotion terms that can be used to denote basic emotions; but only 
five modes - happiness, sadness, anger, fear, and disgust - can refer to them in their unmodified forms. The remaining emotion words denote mild, ordinary, and intense emotions. For example, to be joyful is to feel considerable happiness, whereas to be ecstatic is to feel intense happiness.

According to Johnson-Laird \& Oatley (1989), besides these basic emotions, humans can experience emotions that have an object, a cause, or a goal, and other complex emotions. Emotions that can have an object are typically about someone or something (love, miss, fear, angry with, etc. e.g., James fears John). Caused emotions includes words that describe feelings with known causes (e.g., glad, sorrow, panic, furious, disgust). Causative emotions (e.g., excite, provoke, stir, overwhelm), on the other hand, express the relation between the cause of an emotion and the person who experiences it. The next category displays emotions that often function as motives that lead to characteristic behaviours designed to achieve goals. For example, the achievement of a goal produces happiness, which can be denoted by words such as inclination, desire, need, etc. Unfulfilled goals may lead to sadness or to anger, and these states can be denoted by words such as discontent, disappointment, frustration, etc. The final category encompasses complex emotion (regret, embarrassment, shame, etc.). Thus the remaining 481 emotion terms refer to these categories of emotion, but all of them depend on the five basic modes.

It seems then that the lexicon of emotions in English is organized in a semantic field that is based on five emotional modes-happiness, sadness, anger, fear, and disgust. This set of basic emotions is very similar to other recent proposals and comprises all the basic emotions assembled. In particular, these basic modes of emotions are similar to Ekman et al. (1969)'s list of emotions (except surprise which Johnson-Laird and Oatley did not consider to be an emotion) 
that they consider to be basic as they have distinct nonverbal displays and thus exist in all humans across different societies and cultures, including literate and preliterate cultures (Ekman \& Friesen 1971).

Unlike other theorists who identify meticulous differences between emotions and other phenomena, namely moods, sentiments, feelings, and personality traits (Wierzbicka 1999, Ben-Ze'ev 2000, Pavlenko 2005, Yasunari 2018), for Johnson-Laird and Oatley, basic emotions comprise all these phenomena. For example, an individual can be described as irritable if he or she is currently angry, or in an angry mood, or has a general disposition to be angry. They explain that basic emotion terms can be used to refer to moods or to emotional types of personality because "moods and personality types do not have a discernible cognitive cause. Both depend on emotion modes, and it follows that the vocabulary of basic emotions should provide descriptions of moods and personalities." (Johnson-Laird \& Oatley 1989: 98).

\subsection{Defining Moroccan Arabic}

MA refers to the variety spoken by the majority of Moroccans except the $10 \%$ who are monolingual Berbers (Youssi 1983). As the name indicates, MA is historically related to Classical Arabic (CA). Hence, like CA, MA belongs to the Semitic branch of the AfroAsiatic language family (Ennaji et al. 2004, Feras 2015, Mahmoud 2016, Nasser 2017, Mahmoud 2018, Boubekri 2019). Although it shares many properties with classical Arabic, especially at the lexical level, MA is distinct from Classical Arabic as well as from the varieties of the Middle East (Ennaji et al. 1994). This deviation of MA from CA is due to its direct contact with Berber which has influenced its sound pattern; morphology and lexicon (Ech-charfi 
92 The Universality and Cultural Specificity of Emotions through

2018).

MA stands in a diglossic relationship with Classical Arabic (Ferguson 1959). Classical Arabic enjoys a higher and prestigious status in Morocco because it is the language of basic education; And it is the language used in formal occasions, administration, and writing purposes. By contrast, MA is used in informal settings for daily conversations and transactions. Hence, the linguistic continuum in Morocco is implicitly interpreted as divided into two levels: a lower level referred to as 'Darija' or colloquial Arabic, and a higher level representing classical or standard Arabic. This view has been criticized by several scholars, especially foreign ones (for an overview see Ech-charfi 2017). According to these scholars, the linguistic situation related to the Arabic language cannot be studied by assuming only two levels of Arabic because the discourses produced by Arabic speakers, either written or oral, colloquial or standard, are often a mix of different features, some of which belong to Classical Arabic, and some belong to a lower spoken variety, but it is difficult to classify the text as belonging to the former or the latter. Hence, scholars have identified different levels of Arabic, but they do not agree on the number of these levels.

To start with, Youssi (1992), who studies the Arabic variety spoken in Morocco, concludes that there are three varieties of Arabic in Morocco: the colloquial variety for daily communication, a standard variety for reading and writing and specialized communication, and a middle variety for communication between educated people. Although this middle variety is generally characterised by borrowing vocabulary from Classical Arabic, it is influenced by the colloquial sound system and grammatical structure. Hence, each Arab country has its own middle variety. On the other hand, Badawi (1973, as cited in Ech-charfi 2017) distinguished five linguistic levels in modern Arabic that reflect a number of social factors. These levels are as 
follows: (i) Arabic of the heritage, (ii) modern Arabic, (iii) Colloquial of the educated, (iv) Colloquial of the enlightened and (v) Colloquial Arabic of illiterates. Features of Classical Arabic are prevalent at the first level and then begin in deflation until they are almost non-existent at the last level.

Regardless of these suggested linguistic levels, the variety adopted in this study is the one termed by Youssi (1992) as the 'middle variety'. Hence, when the reader comes across standard Arabic emotion words like 'xaybat Pamal' or 'Pihbat', it should be understood that such standard terms are often used in the speech of educated Moroccan people. Therefore, since the current study targets intermediate and advanced Moroccan learners of English, who have studied Standard Arabic at least for twelve years, it entails that these learners are not unfamiliar with this 'middle variety', which will be referred to as 'Moroccan Arabic' throughout this dissertation.

\section{The Current Study}

\subsection{Participants}

Data were drawn from 29 native speakers of MA, including 25 students studying a master program at the faculty of Education, and four professors as consultants aged between 35 and 50 years. The data were collected in October, 2019.

\subsection{Data Collection}

Listing emotion terms in MA was a challenging task. For there are no studies conducted on the language of emotions in this variety. Hence, all mental states that are supposed to denote emotions in 
94 The Universality and Cultural Specificity of Emotions through

Moroccan Arabic were listed. This took two steps: In the first phase, a preliminary list of emotion words, based on a bilingual dictionary of MA and English (Harrel 2007), was examined. In the second phase, other emotion terms from SA (based on Al-Baalabaki (2007)'s English-Arabic dictionary), which are used by educated MA speakers, were added to the list.

The decision about the emotionness of these terms is based on Oatley et al. (2006: 96) definition of emotion, which can be summarized as follows: (i) It is caused by the conscious or unconscious evaluation of an event as relevant to a concern or goal; It is felt as positive when a goal is advanced and as negative when a goal is impeded; (ii) It consists of action readiness and the prompting of plans, gives priority and a sense of urgency to one or a few kinds of action, and thus interrupts or competes with other mental processes and actions; (iii) It is usually experienced as a distinctive type of mental state, sometimes accompanied or followed by bodily changes, expressions, and actions.

Hence, all the emotion terms that satisfy these criteria were listed. The number of the emotion terms obtained from the two dictionaries is 131 terms which were then reviewed and checked by four highly educated native speakers of MA. These emotion terms are listed in Appendix 2. The terms that have near equivalents in English are translated, and those that have partial equivalents or no equivalents in English are paraphrased.

In order to explore the distribution of the given emotion terms across morphosyntactic categories, the participants were given the list of emotion terms in Appendix 2 and were asked to write sentences using these terms. Thus, obtaining examples of emotions through this corpus based data would allow the researchers to study structural and lexical choices in context. 


\subsection{Data Analysis Procedure}

The descriptive approach was used for the analysis of data. The emotion terms were categorised according to their appearance in the examples provided by the participants, who were asked to use the given emotion in all the probable structures in which these emotion terms can be found. That is, either as adjectives, nouns, complex nouns, adverbs, or verbs (whether they can be used to describe one's emotional states, or ones' emotional state as related to others, or whether they can be causative or caused emotions).

\section{Results}

The analysis of the distribution of emotional terms elicited from the participants indicates that these terms relate to an organised semantic field. They can be divided into coherent categories containing words denoting basic emotions, emotional relations, caused emotions, causes of emotions, emotional goals, and complex emotions. Besides these categories, there is a category of emotion terms that refers to generic emotions in MA. These are: ahasis (feelings), Sawațif (emotions), and mašaSir (sentiments).

As far as basic emotions are concerned, 32 emotion terms are found in the data that can be used to denote basic emotions. These terms include the five basic modes - happiness, anger, fear, sadness, disgust - which refer to basic emotions in their unmodified modes, as well as words denoting basic emotions of differing intensities. Table 1 presents a subset of these emotions with their equivalents in English. 
96 The Universality and Cultural Specificity of Emotions through

Table 1. A Sample of Basic Emotion Words in Moroccan Arabic

\begin{tabular}{|c|c|}
\hline Basic Emotions in MA & English Equivalence \\
\hline buġd & intense hatred \\
\hline gudda & unexpressed anger \\
\hline fezSa & paralyzing fear \\
\hline gaḍab & anger \\
\hline xawf & fear \\
\hline
\end{tabular}

On the other hand, analysis of the examples given by the MA participants reveals that these examples include words that refer to the relation between someone who experiences an emotion and its object. There are 41 words that denote relation emotions. Table 2 presents some examples of these terms.

Table 2. Relation Emotions in MA and Their Equivalence in English

\begin{tabular}{|c|c|}
\hline Relation Emotions in MA & English Equivalence \\
\hline ؟šeq & to adore \\
\hline$\hbar a b$ & to love \\
\hline tweћeš & to miss \\
\hline htaqer & to contempt \\
\hline ğ̣eb & to be angry with \\
\hline
\end{tabular}

Causative emotions, on the other hand, are the largest category in the emotion lexicon of MA as found in the examples given by the particpants in this study. They express the relation between the cause of an emotion and the person who experiences it, e.g., "Amine farreh 
babah" (literally; Amine brought happiness to his father). Most often, words that denote this attribute of emotions are realized by doubling the middle syllable of caused emotions (e.g., $\hbar z e n$ 'got sad', hazzen 'to make someone sad'; ndem 'felt sorry for doing something'; naddem 'to make someone feel sorry for doing something'. 86 words that denote causative emotions are counted in the data. Table 3 shows a sample of them.

Table 3. A Sample of Causative Verbs in MA

\begin{tabular}{|c|c|}
\hline Causative Verbs in MA & English Equivalence \\
\hline farreћ & to make someone happy \\
\hline zennen & to make someone mad \\
\hline gaḍ & to make someone angry \\
\hline hadden & to make someone calm \\
\hline hraj & to embarrass someone \\
\hline
\end{tabular}

Moreover, most of the causative verbs above can also depict the argument as undergoing the action. This is done by the addition of the morpheme $\{\mathrm{t}\}$, which can be translated 'as' (got) + the past participle of the above 'verbs' (e.g., žennen 'to make someone mad', $t$-žennen 'got mad'; ?allem 'to make one suffer', trallem 'to suffer'; faže? 'to surprise someone', tfaže? 'to get surprised'.

Other verbs, however, for which the above rule cannot be applicable, but denote caused emotions are also found the data. These are ergative verbs, such as freh 'to get happy'; ž 4 er 'to get enraged'. This category of verbs, besides other emotion words, constitute the category of caused emotions. It is the category with the second largest number of words that describe feelings with known 
98 The Universality and Cultural Specificity of Emotions through

causes (78 words). Table 4 displays some examples of them:

Table 4. Caused Emotions in MA

\begin{tabular}{|c|c|}
\hline Caused Emotions in MA & English Equivalence \\
\hline freћ & cheered \\
\hline našat & enjoyment \\
\hline meћna & sorrow \\
\hline saxet & indignant \\
\hline gaḍeb & angry \\
\hline
\end{tabular}

The next category of emotions grouped on the basis of the given examples by the participants includes emotions related to goals. They often function as motives that lead to characteristic behaviours designed to achieve goals. There are 30 words that denote emotional goals. Table 5 presents a sample of them:

Table 5. A Sample of Words Denoting Emotional Goals in MA

\begin{tabular}{|c|c|}
\hline Emotion Goals in MA & English Equivalence \\
\hline rag்ba & desire \\
\hline irada & $\begin{array}{c}\text { to have a goal, which if attained causes } \\
\text { happiness }\end{array}$ \\
\hline tharreq & irritable desire to do something; to long for \\
\hline iћbaaț & sadness caused by failure to achieve goal \\
\hline
\end{tabular}

The final category of emotion terms found in the data includes complex emotions. According to Johnson-Laird \& Oatley (1989), complex emotions are experienced as a result of high-level self- 
evaluations. They concern one's own past actions, one's current situation, or one's goals. For example, to feel regret is to feel sad because you judge that your past actions, or inactions, were wrong; to be bored is to be mildly depressed by your lack of purpose or goals; to feel a sense of belonging is to feel happy that one fits in with a group, whereas to feel lonely is to feel sad because one has no company. There are 46 words in the examples provided by the participants that denote complex emotions. A sample of them is presented in Table 6:

Table 6. A Sample of Words Denoting Complex Emotions in MA

\begin{tabular}{|c|c|}
\hline $\begin{array}{l}\text { Complex Emotion } \\
\text { in MA }\end{array}$ & English Equivalence \\
\hline denb & $\begin{array}{l}\text { shame as a result of evaluating one's past } \\
\text { performance as morally wrong }\end{array}$ \\
\hline ћsed & $\begin{array}{l}\text { hatred of someone because one desires some } \\
\text { of their properties or possessions (envy) }\end{array}$ \\
\hline šafaqa & $\begin{array}{l}\text { sadness for (and understanding of) someone as } \\
\text { a result of imagining oneself in their situation }\end{array}$ \\
\hline ta?nib ḍamir & $\begin{array}{l}\text { sadness as a result of evaluating one's past } \\
\text { performance as morally wrong (remorse) }\end{array}$ \\
\hline
\end{tabular}

\section{Discussion and Conclusion}

In this study, we attempted to explore the emotion lexicon and its semantic organization in MA. Based on various sources, we listed up to 315 emotion terms in this variety. These emotions are analysed in terms of Johnson-Laird \& Oatley (1989)'s approach. The analysis 
shows that, just like English, the emotion lexicon of Moroccan Arabic relates to an organized semantic field that includes seven main types of emotion words which can denote generic emotions, basic emotions, emotional relations, caused emotions, causatives, emotional goals, and complex emotions. The highest category, causative emotions, reveals that emotions arise as relational phenomena, embedded in social situations and taking place between people.

Although the analysis of the MA emotion terms confirms Johnson-Laird \& Oatley (1989)'s theory of emotions as well as Ekman and his colleagues' hypothesis of basic emotions, the semantic organisation of the MA emotions, based on the examples found in the native speaker corpus reveals that emotions can also be socially constructed since most of the emotion terms are either relational or causative. Hence, the finding of the study also supports the social perspective of emotions.

According to Averill (1980: 309), "emotions are not just remnants of our phylogenetic past, nor can they be explained in strictly physiological terms. Rather, they are social constructions, and they can be fully understood only on a social level of analysis" (emphasis in original). Along the same line, Mosquera et al. (2002: 3) state that "emotions are interpreted, experienced, and expressed differently depending on the social and cultural context in which they occur, they clearly cannot be universal."

Other social constructionists also maintain that emotions are socially learned in the process of social discourse and social practices, according to culturally specific concerns about identity, morality, and social structure (Averill 1985, Lutz \& White 1986, Mesquita 2003). As pointed out by Oatley (1993: 341), "each culture has patterns of emotions that are somewhat distinctive, that derive from social practices, and that convey meanings and effects to 
members of that culture". These socially learned processes account for the difference in emotions across cultures.

\section{References}

Al-Baalabaki, M. 2007. Al-Mawrid, A Modern English-Arabic Dictionary. Beirut: Dar el-Ilm Lil-Malayen.

Averill, J. 1980. A Constructivist View of Emotion. In R. Plutchik \&

H. Kellerman (eds.), Emotion: Theory, Research and Experience: Vol. I. Theories of Emotion 305-339. New York: Academic Press.

Averill, J. 1985. The Social Construction of Emotion: With Special Reference to Love. In K. Gergen \& K. Davis (eds.), The Social Construction of the Person 89-109. New York: Springer-Verlag.

Badawi, E. 1973. Mustawayat al-arabiyya l-mu'assira fi misr. Cairo: Daral-ma'arif.

Ben-Ze'ev, A. 2000. The Subtlety of Emotions. Cambridge, MA: MIT Press.

Boubekri, A. 2019. Conditionals in Moroccan Arabic. Journal of Universal Language 20.1, 1-38 (https://doi.org/10.22425/jul.2019. 20.1.1).

Darwin, C. 1872/1998. The Expression of Emotions in Man and Animals. 3rd edition. New York: OUP.

Ech-charfi, A. 2017. Al-lugia wa al-lahja madxal li s-susyu lisaaniyya:t al-Sarabiyya. Montréal: Université de Montréal.

Ech-charfi, A. 2018. An Amazigh Substrate in Moroccan Arabic: A Sociolinguistic Reconstruction of Agentives. International Journal of Arabic Linguistics 4.1, 103-137.

Ekman, P. et al. 1969. Pan-Cultural Elements in Facial Display of

Emotions. Science 164.3875, 86-88 (https://doi.org/10.1126/ 
102 The Universality and Cultural Specificity of Emotions through

science.164.3875.86).

Ekman, P. \& W. Friesen. 1971. Constants across Cultures in the Face and Emotion. Journal of Personality and Social Psychology 17.2, 124-129 (https://doi.org/10.1037/h0030377).

Ennaji, M. et al. 1994. Applications of Modern Linguistics. Casablanca: Afrique Orient.

Ennaji, M. et al. 2004. A Grammar of Moroccan Arabic. Fès: Université Sidi Mohamed Ben Abdellah.

Feras, S. 2015. Case Variation from the Perspective of Syntactic Typology \& Universals: Accusative Subjects in Standard Arabic. Journal of Universal Language 16.1, 95-129 (https://doi.org/ 10.22425/jul.2015.16.2.95).

Ferguson, C. 1959. Diglossia. Word 15, 325-340 (https://doi.org/ 10.1080/00437956.1959.11659702).

Harrel, R. 2007. A Dictionary of Moroccan Arabic: MoroccanEnglish. Washington DC: Georgetown University Press.

Johnson-Laird, P. \& K. Oatley. 1989. The Language of Emotions: An Analysis of a Semantic Field. Cognition \& Emotion 3.2, 81-123 (https://doi.org/10.1080/02699938908408075).

Lutz, C. \& G. White. 1986. The Anthropology of Emotions. Annual Review of Anthropology 15.1, 405-436 (https://doi.org/10.1146/ annurev.an.15.100186.002201).

Mahmoud, R. 2016. Grammatical and Pragmatic Aspects of Polarity in Arabic Seditious Utterances. Journal of Universal Language 17.2, 21-51 (https://doi.org/10.22425/jul.2016.17.2.21).

Mahmoud, R. 2018. Pragmatic Investment of Figurative and NonFigurative Designations: The Case of the Egyptian Revolution in Arabic and English Contexts. Journal of Universal Language 19.2, 53-83 (https://doi.org/10.22425/jul.2018.19.2.53).

Mesquita, B. 2003. Emotions as Dynamic Cultural Phenomena. In R. Davidson et al. (eds.), The Handbook of the Affective Sciences 
871-890. New York: OUP.

Mosquera, P. et al. 2002. The Role of Honour Concerns in Emotional Reactions to Offences. Cognition and Emotion 16.1, 143-163 (https://doi.org/10.1080/02699930143000167).

Nasser, A. 2017. On Negation and Focus in Standard Arabic: Interface-based Approach. Journal of Universal Language 18.1, 1-34 (https://doi.org/10.22425/jul.2017.18.1.1).

Oatley, K. 1993. Social Construction in Emotions. In M. Lewis \& J. Haviland (eds.), Handbook of Emotions 341-352. New York: Guilford Press.

Oatley, K. et al. 2006. Understanding Emotions. 2nd edition. Oxford: Blackwell.

Pavlenko, A. 2005. Emotions and Multilingualism. Cambridge: CUP. Wierzbicka, A. 1999. Emotions across Languages and Cultures: Diversity and Universals. Cambridge: CUP.

Yasunari, A. 2018. The Role of Questions in Managing Affect and Emotional Involvement in Japanese Conversations. Journal of Universal Language 19.2, 1-27 (https://doi.org/10.22425/jul. 2018.19.2.1).

Youssi, A. 1983. La Triglossie dans la Typologie Linguistique. La Linguistique 2, 71-83.

Youssi, A. 1992. Grammaire et Lexique de l'Arabe Marocain Moderne. Rabat: Wallada.

\section{Appendix}

\section{Appendix 1. MA Sounds Transcriptions}

The majority of consonants in MA are similar to sounds in English. 
104 The Universality and Cultural Specificity of Emotions through

However, there are eight consonants in MA that do not have equivalents in English. The transcription characters for each of these sounds are explained below.

\begin{tabular}{|c|l|l|}
\hline MA Sounds & \multicolumn{2}{|c|}{ Sound Description } \\
\hline $\mathrm{d}$ & voiced alveolar stop & $\begin{array}{l}\text { These sounds are pronounced } \\
\text { like their non-emphatic } \\
\text { counterparts, but with a lower } \\
\text { pitch and a greater tension in } \\
\text { the tongue and throat. }\end{array}$ \\
\hline $\mathrm{s}$ & voiceless alveolar fricative \\
\hline $\mathrm{t}$ & the Arabic emphatic " $\mathrm{t}$ " & \\
\hline $\mathrm{q}$ & voiceless uvular stop \\
\hline $\mathrm{x}$ & voiceless uvular fricative \\
\hline$\dot{\mathrm{g}}$ & voiced uvular fricative \\
\hline $\mathrm{h}$ & voiceless pharyngeal fricative \\
\hline $\mathrm{c}$ & voiced pharyngeal fricative \\
\hline
\end{tabular}

\section{Appendix 2. List of Emotion Terms in Moroccan Arabic}

\begin{tabular}{|ll|l|}
\hline \multicolumn{2}{|c|}{ Emotion Nouns in MA } & \multicolumn{2}{|c|}{ Definition in English } \\
\hline 1. & Palam & sorrow, pain \\
\hline 2. & Pamal & hope \\
\hline 3. & Paman & security \\
\hline 4. & bahja & joy \\
\hline 5. & bug்d & aversion \\
\hline 6. & dehša & astonishment \\
\hline 7. & dell & humiliation \\
\hline 8. & denb & guilt \\
\hline 9. & dağt & stress \\
\hline
\end{tabular}




\begin{tabular}{|c|c|c|}
\hline & daym & $\begin{array}{l}\text { feeling sadness as a result of remembering one's } \\
\text { happiness }\end{array}$ \\
\hline 11. & faraž & relief \\
\hline 12. & feg $\mathrm{fa}_{\mathrm{a}}$ & unexpressed anger \\
\hline 13. & feqsa & unexpressed rage \\
\hline 14. & ferћa & happiness for a known reason \\
\hline 15. & fez@a & fright \\
\hline 16. & ftixar & pride \\
\hline 17. & gorha & intense grief \\
\hline 18. & ġạ̣ab & anger \\
\hline 19. & ġassa & intense anger that is not expressed \\
\hline 20. & ġayḍ & intense hatred \\
\hline 21. & gem & sad mood \\
\hline 22. & gira & jealousy \\
\hline & gudda & $\begin{array}{l}\text { suppressed anger as a result of evaluation that } \\
\text { one has been wronged }\end{array}$ \\
\hline & gurba & $\begin{array}{l}\text { feeling sad as a result of being far from home } \\
\text { and relatives }\end{array}$ \\
\hline 25. & hana? & peace and happiness \\
\hline 26. & hayajan & intense anger \\
\hline 27. & hem & sad mood \\
\hline 28. & histiria & intense and uncontrollable anger \\
\hline 29. & htimam & caring \\
\hline 30. & Hudu? & calm \\
\hline 31. & huam & love \\
\hline 32. & ћamaas & enthusiasm \\
\hline 33. & hanan & affection \\
\hline 34. & hanin & yearning \\
\hline 35. & ћașra & intense regret \\
\hline & ћešma & $\begin{array}{l}\text { positive embarrassment especially of women in } \\
\text { presence of strangers }\end{array}$ \\
\hline
\end{tabular}


106 The Universality and Cultural Specificity of Emotions through

\begin{tabular}{|c|c|c|}
\hline & ћub & love \\
\hline 38 & ћugra & feeling sadness, anger, humiliation, and injustice \\
\hline 3 & ћuzn & sadness \\
\hline 40 & hsed & envy \\
\hline 41 & ћqed & spite \\
\hline 42. & htiqaar & contempt \\
\hline 43 & hya & positive embarrassment towards elderly people \\
\hline 44 & ћšuma & shameful behavior \\
\hline 45 & ihaana & humiliation \\
\hline 46 & ihmal & neglect \\
\hline 47 & imtiৎaaḍ & resentment \\
\hline 48 & inbihaar & fascination \\
\hline 49 & iћbaat & frustration \\
\hline 50 & ihraj & embarrassment \\
\hline 51 & irhab & terror \\
\hline 52 & istimta؟ & enjoyment \\
\hline 53 & isterxaa & relief \\
\hline 54 & itara & excitement \\
\hline 55 & iYžaab & feeling a liking for someone \\
\hline 56 & infiSal & intense anger for a known \\
\hline 57 & injidab & emotional attraction \\
\hline 58 & intiqas & contempt \\
\hline 59 & inziৎaj & annoyance \\
\hline 60 & išmiৎzaz & disgust \\
\hline 61 & kaSia & intense anger \\
\hline 62 & kti?aab & depression \\
\hline 63 & kurh & hatred \\
\hline 64 & lahfa & eagerness \\
\hline 65 & maraara & bitterness \\
\hline 66 & mawadda & mutual liking, cordiality \\
\hline
\end{tabular}




\begin{tabular}{|c|c|c|}
\hline & mebhuḍ & feeling amazed \\
\hline 68. & meћna & distress \\
\hline 69. & medGur & panicked \\
\hline 70. & menbud & feeling isolated \\
\hline 71. & meßyuf & disgusting \\
\hline 72. & mreg & to be extremely embarrassed \\
\hline 73. & mћenna & compassion towards close people \\
\hline 74. & mšuwweš & concerned \\
\hline 75 . & mufaža?a & surprise \\
\hline 76. & muqt & intense hatred \\
\hline 77. & muwaasat & sympathy \\
\hline 78. & muSanat & suffering \\
\hline 79 . & mYanni & $\begin{array}{l}\text { feeling proud as a result of a relative's great } \\
\text { achievements }\end{array}$ \\
\hline 80. & našat & pleasure as a result of an activity \\
\hline 81. & ndama & regret \\
\hline 82. & nufur & intense hatred \\
\hline 83. & qalaq & worry \\
\hline 84. & rahba & fear of greatness of a place or person \\
\hline 85 . & raha & relaxed mild happiness \\
\hline 86. & raћma & compassion \\
\hline 87. & ragiba & desire \\
\hline 88. & re?fa & compassion \\
\hline 89. & riḍa & satisfaction \\
\hline 90. & rofb & intense fear \\
\hline 91. & saSada & happiness \\
\hline 92. & saxt & anger of parents on their children \\
\hline 93. & surur & gladness \\
\hline 94. & ședma & shock \\
\hline 95. & šahwa & intense desire for sex \\
\hline
\end{tabular}


108 The Universality and Cultural Specificity of Emotions through

\begin{tabular}{|c|c|c|}
\hline & šafaqa & pity \\
\hline 97. & šaġaf & intense interest and excitement \\
\hline 98. & šawq & longing for someone or something \\
\hline 99. & šemta & hatred and anger as result of being deceived \\
\hline 100 & ta?nib amir & remorse \\
\hline 101. & tafa?ul & optimism \\
\hline 102. & taša?um & lack of hope \\
\hline 103. & tạasa & unhappiness \\
\hline 104 & taYațuf & sympathy \\
\hline 105 & tbahdila & humiliation \\
\hline 106 & tehwil & causing one fear \\
\hline 107. & tehfiz & motivation \\
\hline 108 & teqliqa & sadness and anger \\
\hline 109. & tešwiq & intense excitement for a known reason \\
\hline 110 & tšefya & being pleased as someone is in troubles \\
\hline 111. & taslia & enjoyment \\
\hline 112. & taSalluq & concern \\
\hline 113. & tawattor & tenseness \\
\hline 114 & tkeškiša & anger expressed by saying bad things \\
\hline 115 & țuma?nina & confidence \\
\hline 116. & waћda & loneliness \\
\hline 117. & wel؟a & passion; fondness of something \\
\hline 118. & weћša & missing someone \\
\hline 119. & ye?s & hopelessness \\
\hline 120 & zhaaf & sad and depressed \\
\hline 121. & žeSra & rage \\
\hline 122. & xal؟a & fright \\
\hline 123. & xayba & disappointment \\
\hline 124 & xawf & fear \\
\hline 125 & Saar & intense shame \\
\hline
\end{tabular}


Khalid Elasri \& Abdelhakim Boubekri 109

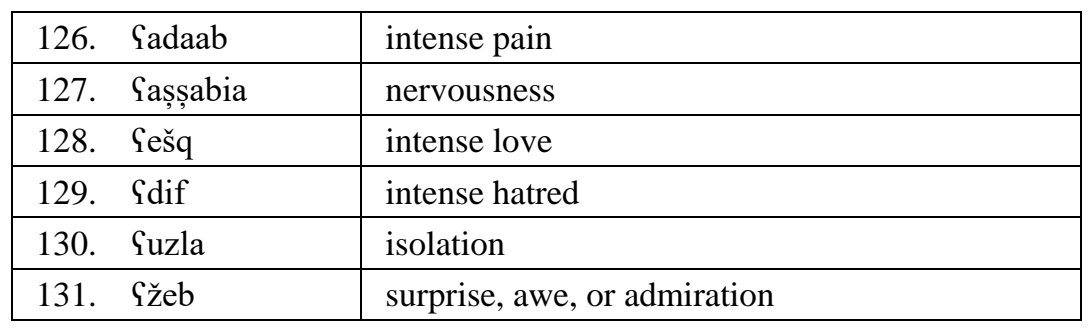

